\title{
Decompression without Fusion for Low-Grade Degenerative Spondylolisthesis
}

\author{
Jason Pui Yin Cheung, Prudence Wing Hang Cheung, Kenneth Man Chee Cheung, Keith Dip Kei Luk \\ Department of Orthopaedics and Traumatology, The University of Hong Kong, Hong Kong, SAR, China
}

\begin{abstract}
Study Design: Retrospective series.
Purpose: Assess results of decompression-only surgery for low-grade degenerative spondylolisthesis with consideration of instability. Overview of Literature: There is no consensus on whether fusion or decompression-only surgery leads to better outcomes for patients with low-grade degenerative spondylolisthesis. Current trends support fusion but many studies are flawed due to over-generalization without consideration of radiological instability and their variable presentations and natural history.

Methods: Patients with surgically treated degenerative spondylolisthesis from 1990-2013 were included. Clinical and radiological instability measures were included. Any residual or recurrence of symptoms, revision surgery performed and functional outcome scores including the numerical global rate of change scale, visual analogue scale, and modified Barthel index were measured. Followup periods for patients were divided into short-term ( $<5$ years), mid-term ( $5-10$ years) and long-term ( $>10$ years).

Results: A total of 64 patients were recruited. Mechanical low back pain was noted in 48 patients and most (85.4\%) had relief of back pain postoperatively. Radiological instability was noted in 4 subjects by flexion-extension radiographs and 12 subjects with prone traction radiographs by increased disc height and reduction of olisthesis and slip angle. From the results of the short-term, midterm and long-term follow-up, reoperation only occurred within the first 5-year follow-up period. All functional scores improved from preoperative to postoperative 1-year follow-up.

Conclusions: Decompression-only for low-grade degenerative spondylolisthesis has good long-term results despite instability. Further higher-level studies should be performed on this patient group with radiological instability to suggest the superior surgical option.
\end{abstract}

Keywords: Low-grade; Degenerative; Spondylolisthesis; Decompression; Without; Fusion

\section{Introduction}

The decision on whether to fuse in low-grade degenerative spondylolisthesis usually depends on whether there is mechanical back pain or signs of radiological instability. However, there is no strict guideline or consensus as "instability" does not carry a common definition and can mean different things to a clinician (mechanical back pain), radiologist (movement between the spinal segments) or bioengineer (biomechanical instability of spinal segments). Despite these difficulties in decision making, the current trend in the literature still supports fusion for all cases of spondylolisthesis [1-8]. However, detailed examination of these studies reveals many methodologi-

\footnotetext{
Received Apr 26, 2015; Revised May 25, 2015; Accepted Jun 17, 2015

Corresponding author: Keith Dip Kei Luk

Tam Sai Kit Endowed Chair in Spine Surgery, Department of Orthopaedics and Traumatology, University of Hong Kong,

5/F Professorial Block, Queen Mary Hospital, Pokfulam, Hong Kong SAR, China

Tel: +852-2255-4254, Fax: +852-2817-4392, E-mail: hrmoldk@hku.hk
} 
cal flaws regarding case recruitment, assessment details, symptomatology segregation and surgical indications. Many of these studies group all slips into one disease entity and overgeneralize their management, when in fact degenerative spondylolisthesis covers a spectrum of varying presentations and natural history.

Laminectomy and fusion reportedly produce better outcomes in all cases of spondylolisthesis $[1-3,5,6]$. On the contrary, results from the studies show no advantage for fusion in the short-term follow-up, with increased prevalence of complications such as non-union. At longer follow-up, better results are noted only if fusion is successful. In these studies, fusion was performed for all cases of spondylolisthesis irrespective of the grade or any evidence of radiological instability.

In the Tango registry, better results with fusion were evident in patients with back or leg pain [4]. However, similar flaws were notable, with over-generalization of spondylolisthesis. In addition, patients with combined back and leg pain were all listed in the leg pain category. Thus, patients with predominant back symptoms caused by instability may have inflated the fusion results of the leg pain group. Another potential problem with the registry data is that patients with fusion performed for degenerative scoliosis may have been included. In these cases, mechanical back pain was caused by coronal or sagittal imbalance rather than instability, which is better suited for deformity correction and fusion surgery.

In the Spine Patient Outcomes Research Trial (SPORT) [8], better outcomes were found for fusion at 4 years of follow-up. Yet, there were no indicators whether the patient had back or leg pain, or information regarding the severity of the symptoms, the degree of slip and evidence of clinical or radiological instability. In another SPORT study [7] comparing operative and nonoperative treatment for spondylolisthesis, better outcomes were found with nonoperative treatment for hypermobile spinal segments based on Hanley's criteria [9] as compared to stable slips. Although the authors were unable to explain this finding, the results suggest that the need for fusion, even for the hypermobile group, may not be compelling.

The optimal management scheme for low-grade spondylolisthesis is still unknown. Patients may benefit from decompression alone without fusion. Hence, the aim of this study is to review the results of decompression-only surgery for low-grade degenerative spondylolisthesis with an emphasis on the outcomes in patients with either clini- cal or radiological evidence of instability.

\section{Materials and Methods}

Following approval by the local Institutional Review Board, case notes from all patients with Meyerding grade 1 degenerative spondylolisthesis of the lumbar spine were traced from 1990-2013. The inclusion criterion was all patients who underwent decompression-only surgery with completion of at least 3 months of conservative treatment (active modalities with physiotherapy training and analgesic treatment). Subjects with congenital deformities, previous infections and surgery of the lumbar spine, tumors or trauma of the lumbar spine were excluded. Subjects without traceable preoperative dynamic radiographs or postoperative functional assessment were also excluded. Study parameters gathered from the patients included age at surgery, gender, clinical symptomatology, level of spondylolisthesis, any instability in the spinal segment, type of surgery done, length of follow-up, any residual or recurrence of symptoms and if so when, any revision surgery performed and at which level and the time interval between the index surgery and the revision surgery. For the clinical symptomatology, the categories used included leg symptoms (claudication, radiculopathy, sciatica) only, leg symptoms with mechanical back pain and/or neurological deficit. Mechanical back pain was defined as back pain that was aggravated by change in posture or walking.

For the surgical procedure, only subjects with fenestration by laminotomy and medial facetectomy for the involved levels were included. A midline approach was adopted for all cases. Facet joint capsules and midline spinous process and interspinous ligaments were preserved in all cases. No more than one-third medial facetectomy was performed using a chisel. No patients received laminectomy or discectomy to avoid further exacerbation of disc degeneration or the spondylolisthesis.

Radiological instability was defined by evidence of increased degree of slip, change in slip angle and disc height on preoperative flexion-extension radiographs. Instability was also defined by a reduced degree of slip, change in slip angle and disc height on preoperative prone traction radiographs as described by Luk et al. [10]. For prone traction films, patients were placed prone on a traction table and a traction force half of the body weight was applied through a set of chest and pelvic straps before cross-table lateral radiographs were taken. For measurement of the 


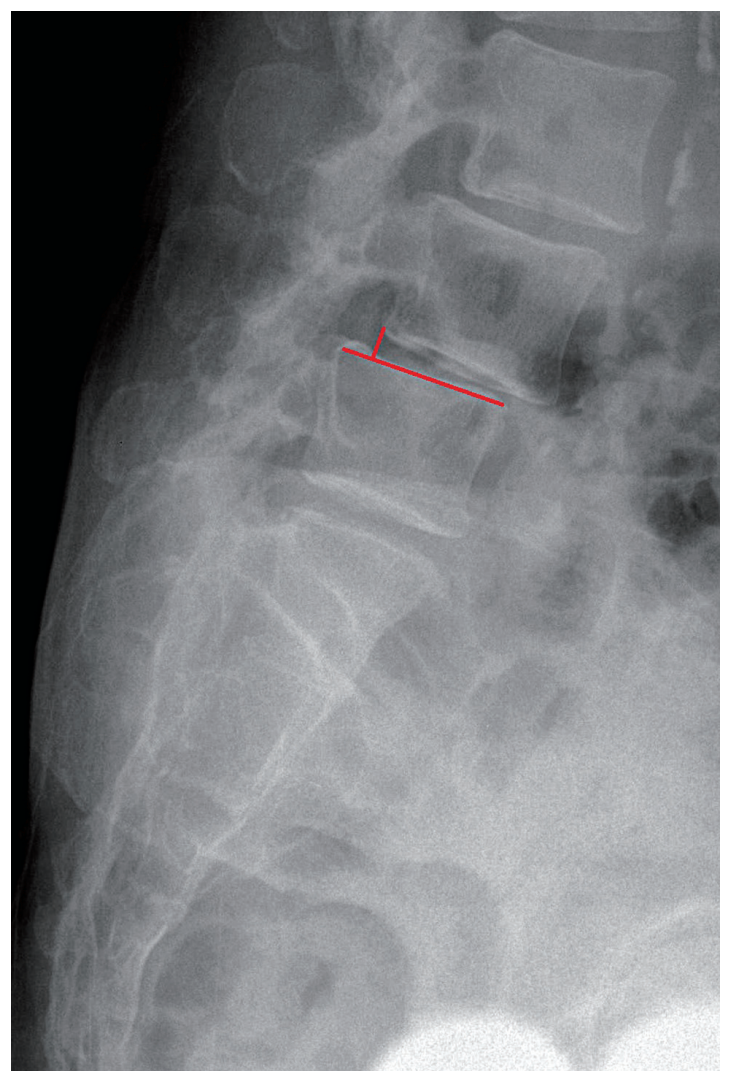

Fig. 1. Measurement of degree of slip.

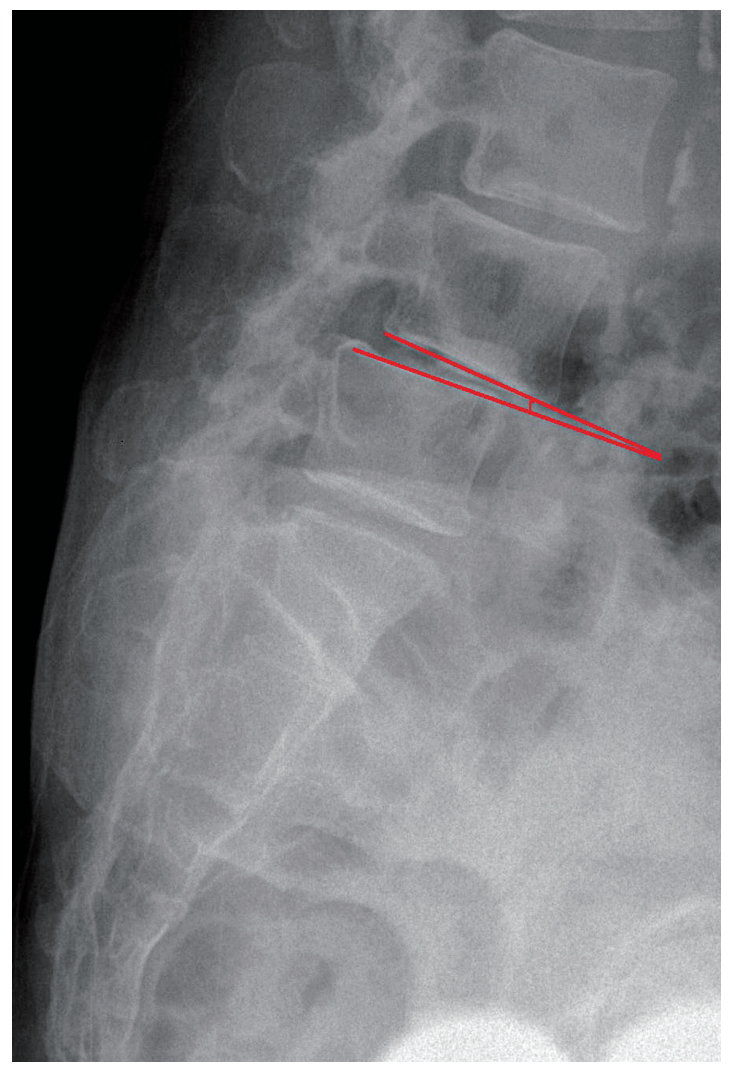

Fig. 2. Measurement of slip angle. degree of slip (Fig. 1), a line was dropped from the posterior border of the cranial vertebrae to the caudal vertebrae. The distance from this point to the posterior border of the caudal vertebrae was divided by the total vertebral body width of the caudal vertebrae. Change of $4 \mathrm{~mm}$ in translation was considered instability. The slip angle of a L5-S1 spondylolisthesis was measured by a line perpendicular to the posterior aspect of sacrum and line drawn along inferior end of the endplate of L5. In cranial segments (Fig. 2 ), the angle was made by the superior endplate of caudal vertebrae and inferior endplate of cranial vertebrae. Taking into account for measurement errors usually present for measuring angles [11], changes of slip angle $>5^{\circ}$ was considered unstable. For measurement of the disc height (Fig. 3), a line was dropped from the midline inferior endplate of the cranial vertebrae to the upper endplate of the caudal vertebrae. A ratio between this distance and the midline vertebral height of the cranial vertebrae was compared on dynamic views. Normal Asian lumbar spine disc profiles $[12,13]$ of gradual increase from L1-L2 to L4-L5 followed by decrease to L5-S1 was used as the baseline comparison. Any change in this relationship was consid-

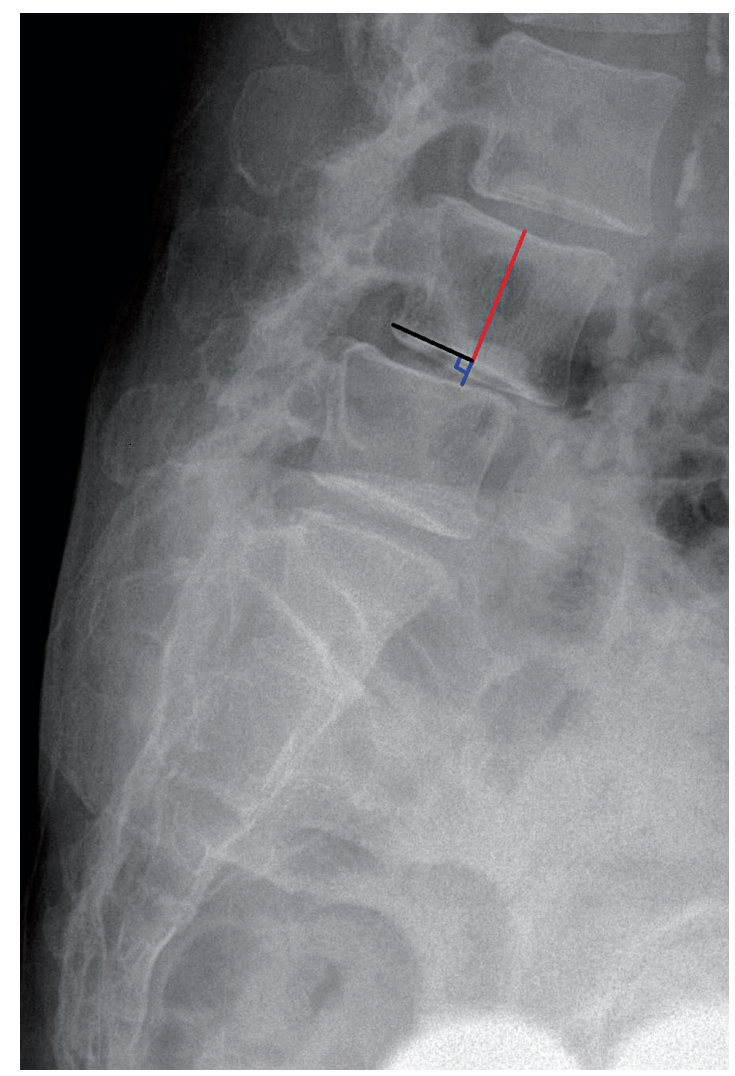

Fig. 3. Measurement of disc height. 
ered unstable. In prone traction films, immediate change in disc height was evidence that the anterior column supporting axial compression was deficient. Currently, there is no consensus on what is considered instability on the prone traction films. Thus, similar to flexion-extension radiographs, any increase in disc height, reduction of olisthesis or reduction of slip angle was noted in the prone traction radiographs for the purposes of this study.

Due to the retrospective nature of this study, patients could have received decompression-only surgery in the presence of radiological instability as the indication of surgery was not standardized. Any residual symptoms was noted as symptoms that persisted after surgery. Recurrence of symptoms indicated any new symptoms that occurred after surgery or symptoms that have recurred after completely subsiding after surgery. Analysis of these subjects was performed for the short-term $(<5$ years $)$, mid-term (5-10 years) and long-term ( $>10$ years) followup after the index surgery. Functional assessment of all patients were performed immediate preoperatively after conservative treatment has completed and at postoperative 1-year as our usual follow-up protocol. Numeric global rate of change scale (NGRCS), visual analogue scale (VAS) and modified Barthel index (MBI) were used for assessment.

Descriptive data was listed in mean scores with standard deviation (SD). Statistical analysis was performed with paired t-test. A $p$-value of $<0.05$ was considered significant. 95\% Confidence interval (CI) information was listed.

\section{Results}

Sixty four patients were recruited for this study. Details for each parameter are listed in Table 1 and radiological measurements are provided in Table 2. Radiological instability by flexion-extension radiographs was noted in 4 (6.3\%) subjects indicated by increased disc height and reduction of degree of olisthesis and slip angle. In 60 (93.8\%) subjects, dynamic radiological examination did not fulfil our instability criteria. Only 12 patients had prone traction radiographs preoperatively and all had increased disc height and some reduction in the degree of olisthesis, which was more than what was expressed on the flexionextension radiographs. No patients had aggravation of the slip on the postoperative 1-year neutral standing lateral radiographs as compared to preoperative radiographs.
This relationship existed for the degree of slip $(p=0.21$, 95\% CI: -1.2 to 0.3 ), slip angle ( $p=0.29,95 \%$ CI: -0.7 to 2.3 ) and disc height ( $p=0.25,95 \%$ CI: -0.4 to 1.6 ). Patients were subclassified into the short-term $(<5$ years $)$, midterm (5-10 years) and long-term ( $>10$ years) follow-up after the index surgery for outcome analysis. The NGRCS, VAS and MBI all improved from preoperatively to postoperative 1year (Table 3).

\section{Short-term follow-up}

Twenty-four subjects were classified into the short-term follow-up. Preoperatively, only one (4.2\%) of these subjects had radiological instability but mechanical low back pain was noted among 22 of these patients. Postoperatively during follow-up, eleven patients had residual symptoms and only 6 (27.2\%) had residual back pain. Seven patients had recurrence of symptoms. Of these, 5 patients had leg pain and 2 had back pain, one of which had radiological instability at the adjacent level. Two of these patients required discectomies to treat L5-S1 disc prolapses caudal to the index operated level at L4-L5 within one year of the index surgery. None of the patients required fusion surgery. At the short-term follow-up, most patients with decompression-only had good relief of symptoms including the preoperative mechanical back pain. Only two patients required further surgery for prolapsed discs that might not have been related to the original pathology.

\section{Mid-term follow-up}

At mid-term follow-up, there were 26 patients. Only 2 (7.7\%) had preoperative radiological instability. Mechanical low back pain was noted among 18 (69.2\%) patients preoperatively. After surgery during follow-up, residual symptoms were noted in 8 patients. Only one patient had residual back pain (5.6\%). Recurrence of symptoms occurred in 8 patients. Of these, 2 patients had back pain and 3 patients developed radiological instability. Reoperation was required in 4 patients. All 4 cases had their reoperation within the 5-year follow-up period and none of the cases required further reoperation up to 10-year follow-up. One required reoperation for a prolapsed intervertebral disc, one had an early epidural hematoma with evacuation and two had intraoperative pars fracture with progression of slips requiring fusion. The mid-term follow-up was similar to the short-term follow-up in that 
Table 1. Clinical parameters

\begin{tabular}{|c|c|c|}
\hline Parameter & Mean mm ( $\pm S D)$ & Percentage $(\%)$ \\
\hline \multicolumn{3}{|l|}{ Sex } \\
\hline Male & 28 & 43.8 \\
\hline Female & 36 & 56.3 \\
\hline Age at surgery & $69.1(8.7)$ & \\
\hline \multicolumn{3}{|l|}{ Symptomatology } \\
\hline Leg pain & 5 & 7.8 \\
\hline Leg and back pain & 9 & 14.1 \\
\hline Leg pain and neurology & 11 & 17.2 \\
\hline Leg and back pain and neurology & 39 & 60.9 \\
\hline \multicolumn{3}{|l|}{ Level of spondylolisthesis } \\
\hline $\mathrm{L} 3 / 4$ & 8 & 12.5 \\
\hline$\llcorner 4 / 5$ & 48 & 74.9 \\
\hline $\mathrm{L} 5 / \mathrm{S} 1$ & 3 & 4.7 \\
\hline $\mathrm{L} 3 / 4$ and $L 4 / 5$ & 4 & 6.3 \\
\hline$L 4 / 5$ and L5/S1 & 1 & 1.6 \\
\hline \multicolumn{3}{|l|}{ Surgery done } \\
\hline 1-level decompression & 30 & 46.9 \\
\hline$>1$-level decompression & 34 & 53.1 \\
\hline Follow-up period (yr) & $7.1(3.8)$ & \\
\hline \multicolumn{3}{|l|}{ Residual symptoms } \\
\hline None & 43 & 67.2 \\
\hline Leg symptoms & 12 & 18.8 \\
\hline Back pain & 3 & 4.7 \\
\hline Leg and back pain & 4 & 6.3 \\
\hline Radiological instability & 2 & 3.1 \\
\hline \multicolumn{3}{|l|}{ Any recurrence } \\
\hline Yes & 18 & 28.1 \\
\hline No & 46 & 71.9 \\
\hline \multicolumn{3}{|l|}{ Recurrence of symptoms } \\
\hline None & 46 & 71.9 \\
\hline Back pain & 3 & 4.7 \\
\hline Leg symptoms & 9 & 14.1 \\
\hline Leg and back pain & 1 & 1.6 \\
\hline Radiological instability & 5 & 7.8 \\
\hline \multicolumn{3}{|l|}{ Any reoperation } \\
\hline Yes & 9 & 14.1 \\
\hline No & 55 & 85.9 \\
\hline \multicolumn{3}{|l|}{ Type of reoperation } \\
\hline Further decompression & 2 & 3.1 \\
\hline Fusion & 6 & 9.4 \\
\hline Epidural steroid injection & 1 & 1.6 \\
\hline \multicolumn{3}{|l|}{ Reoperation at same level } \\
\hline Yes & 10 & 15.6 \\
\hline No & 5 & 7.8 \\
\hline Back complaint & 3 & 4.7 \\
\hline Time interval between index surgery and reoperation (day) & $1,451(1,357)$ & \\
\hline
\end{tabular}

$\mathrm{SD}$, standard deviation. 
Table 2. Radiological measurements

\begin{tabular}{|c|c|c|c|}
\hline Variable & Degree of slip (mm) & Slip angle $\left({ }^{\circ}\right)$ & Disc height (mm) \\
\hline \multicolumn{4}{|l|}{ Preoperative } \\
\hline Extension & $4.8(2.3)$ & $6.7(4.4)$ & $10.3(3.4)$ \\
\hline Flexion & $6.1(2.5)$ & $5.1(3.7)$ & $9.8(3.6)$ \\
\hline Prone traction & $1.1(0.4)$ & $4.1(2.8)$ & $10.8(5.8)$ \\
\hline Postoperative $^{\text {a) }}$ & $5.3(1.7)$ & $5.9(3.4)$ & $9.7(3.0)$ \\
\hline
\end{tabular}

Values are presented as mean ( \pm standard deviation).

${ }^{a}$ These measurements were performed on the neutral lateral standing radiographs at 1 year follow-up.

Table 3. Preoperative and postoperative 1-year functional scores

\begin{tabular}{|c|c|c|c|c|}
\hline Score (range) & Preoperative & Postoperative 1 yr & $p$-value & $\begin{array}{l}95 \% \text { confidence } \\
\text { interval }\end{array}$ \\
\hline Numerical global rate of change scale (-10 to 10$)$ & $2.12(1.99)$ & $8.12(1.63)$ & $<0.001$ & $5.0-7.0$ \\
\hline Visual analogue scale (0-10) & $7.8(1.90)$ & $1.6(1.84)$ & $<0.001$ & $4.8-7.6$ \\
\hline Modified Barthel index $(0-100)^{a)}$ & $84.8(15.8)$ & $95.5(6.63)$ & $<0.001$ & -16.0 to -5.5 \\
\hline Feeding $(0-10)$ & $10.0(0)$ & $10.0(0)$ & - & - \\
\hline Personal hygiene/grooming (0-5) & $4.9(0.5)$ & $5.0(0)$ & 0.33 & -0.3 to 0.1 \\
\hline Dressing $(0-10)$ & $9.9(1.8)$ & $10.6(1.8)$ & 0.13 & -1.6 to 0.2 \\
\hline Chair/bed transfers (0-15) & $12.6(3.9)$ & $14.4(1.5)$ & 0.05 & -3.7 to 0.0 \\
\hline Bowel control $(0-10)$ & $8.3(3.3)$ & $9.8(0.6)$ & 0.07 & -3.2 to 0.2 \\
\hline Bladder control (0-10) & $8.2(3.6)$ & $9.9(0.5)$ & 0.07 & -3.4 to 0.1 \\
\hline Toilet transfers (0-10) & $9.0(2.4)$ & $10.0(0)$ & 0.10 & -2.2 to 0.2 \\
\hline Bathing (0-5) & $3.5(2.0)$ & $5.2(1.2)$ & 0.02 & -3.1 to -0.3 \\
\hline Stair climbing (0-10) & $5.9(4.7)$ & $8.4(4.2)$ & 0.01 & -4.1 to -0.8 \\
\hline Ambulation (0-15) & $10.6(4.9)$ & $13.1(2.8)$ & $<0.01$ & -4.0 to -0.9 \\
\hline
\end{tabular}

Values are presented as mean ( \pm standard deviation).

${ }^{\text {al }}$ For the modified Barthel index, a score of 0-20 indicates total dependence, 21-60 indicates severe dependence, 61-90 indicates moderate dependence, 91-99 indicates slight dependence and 100 indicates independence. Patients with a score of less than 40 are unlikely to go home and a score of 60 is the pivotal score where patients move from dependency to assisted independence. Scores of 60-80 suggests that a patient living alone will need community services and more than 85 suggests that the patient can be discharged to community living.

patients with mechanical back pain had relief of symptoms with decompression surgery alone. In addition, not all patients with radiological instability required fusion surgery.

\section{Long-term follow-up}

At long-term follow-up, there were 14 patients included. Preoperatively, 8 (57.1\%) of them had mechanical back pain. Only one had radiological instability by flexionextension radiography. All 12 patients with preoperative prone traction radiographs were in the long-term followup group. Two patients with long-term follow-up had residual leg pain. No patient complained of residual back pain after surgery. Recurrence of symptoms was noted in 3 patients. Two complained of leg symptoms and one patient developed new radiological instability. Reoperation was required in 2 patients and it occurred within the 5 -year follow-up. Both patients required revision surgery for inadequate decompression. Similar to the previous two follow-up periods, most patients with mechanical back pain were treated successfully with decompression alone and reoperation only occurred within the first 5 years of follow-up [14].

\section{Discussion}

The decision on how to manage degenerative spondylolisthesis is usually based on the symptomatology and 
presence of radiological instability. As degenerative spondylolisthesis is highly variable in presentation and natural history, management should be individualized to each patient. Most will accept decompression-only surgery for patients with pure neurological symptoms without evidence of abnormal motion on flexion-extension radiographs [14]. This is especially indicated for low-grade slips where one of the main mechanisms for nerve root impingement is intervertebral foramen narrowing due to the up-riding superior articular process and arcuate ligaments [15]. Decompression is adequate in these cases by enlarging the foraminal space without causing further progression of the spondylolisthesis. Iatrogenic destabilization of the spinal segment occurs with too much stripping of posterior supporting structures and removal of more than 50\% of facet joints and interspinous ligaments. Our routine method of posterior decompression is laminotomy and medial facetectomy without discectomy. This is an effort to avoid any disruption of the already degenerated intervertebral disc and further progression of the degenerative instability process [16].

The current trends in the literature support fusion for most cases of spondylolisthesis [1-8]. However, most of the evidence is flawed. Meta-analyses or systematic reviews have significant drawbacks to their conclusions because the presentation of spondylolisthesis is variable in the literature. Some studies failed to document any clinical or radiological instability before deciding on fusion, others advocated fusion surgery for mechanical low back pain despite no radiological instability and some suggested fusion for spondylolisthesis without any signs of dynamic instability. Many clinicians regard recurrent, acute episodes of low back pain caused by mechanical stresses as indicative of instability. Yet, mechanical low back pain is not a symptom exclusive to symptomatic spondylolisthesis as its causality may be related to facet joint degeneration, annular tears, nerve root compression or postural instability [17]. From our results of all three follow-up periods, patients with mechanical back pain should not be a main consideration for fusion surgery, as 41 out of 48 patients (85.4\%) with mechanical back pain experienced complete relief of the symptoms after decompression-only surgery. Residual back pain after surgery persisted in only 2 of the patients with preoperative radiological instability. It appears that if reoperation is needed for residual compression, or symptomatic instability after decompressiononly surgery, it occurs within the first 5 years. In addition, not all cases of radiological instability require fusion because the instability observed does not seem to affect the outcome of back pain resolution.

The definition of radiological instability is another debatable issue due to the limitations of the flexion-extension radiograph. Radiological instability is frequently accepted as an objective parameter for consideration of fusion surgery. Flexion-extension lateral radiographs are commonly performed to observe for any excessive movements of the spinal segment beyond what is normally seen. Whether this movement requires fusion or not is still subject to controversy as the presence of movement on these dynamic scans may not equate to clinical symptoms [17-20]. Moreover, presence of a slip or dynamic changes on flexionextension radiographs may not require fusion surgery for good clinical outcomes [21]. There is also no consensus concerning instability. Numerous definitions have been proposed in the literature including those of Panjabi et al. [22], Posner et al. [23] and Hanley [9]. These definitions are usually based on vertebral body translation or change in angulation, as the change of slip angle and loss of disc height indicates a loss of support for the functional spinal unit [24-28]. Furthermore, flexion-extension radiographs may not be able to provoke any segmental movement without changes in the disc height $[10,29]$ while prone traction films are more powerful in eliciting these findings.

The radiological measurements that are discussed here are all based on intervertebral disc pathology. Hence, this is the fundamental reason why dynamic flexion-extension radiographs are inferior to prone traction radiographs for assessment of radiological instability. The main pathomechanism in degenerative spondylolisthesis is a deficiency of the anterior column support due to disc degeneration. Loss of intervertebral disc height translates to the loss of support against axial loads by the anterior spinal column [10] and the subsequent dysfunction of the posterior ligamental complex. The deficient anterior column causes laxity of the surrounding ligamental structures and lead to destabilization of the entire spinal segment and axial instability. The vertebral body slips forward under load. Based on this principle, restoration of the disc height can result in tensioning of the spinal ligaments and a reduction of the spondylolisthesis. Extension radiographs are unable to reverse this mechanism as compared to traction radiographs [10]. Traction radiographs have demonstrated segmental spinal translations even in the absence of flexion-extension movement [29]. Restoration of the 
disc height with prone traction radiographs may be more indicative of instability as shown by its linear relationship with the slip angle, disc area and spondylolisthesis [10].

The authors do admit that no paradigm shifting conclusion can be made in this study based on 12 preoperative prone traction films. Nonetheless, dynamic radiographic instability is more sensitive in prone traction radiographs than flexion-extension radiographs (Fig. 4). The significance and diagnostic cut-off values in these dynamic radiographs are still in question. Despite restoration in disc height and reduction in slip angle in some cases, good results are found with decompression-only surgery. Since there is no clear definition for axial instability, quantification of the degree of disc height restoration and slip angle reduction and correlating it to objective outcome measures will be required in the future to properly utilize traction films. There is likely an instability threshold regarding anterior column deficiency that governs whether a patient requires stabilization. Prospective studies can help further analyze this concept of axial instability and its related management options.

In this study, we focused our analysis on low-grade degenerative spondylolisthesis, which in the current literature has no management consensus. Unlike previous published studies, a strict selection of subjects and definition of radiological instability was considered. This avoided overgeneralizing the management irrespective of the grade of the slip and spine stability. Our study provides evidence that decompression-only surgery has good long-term results despite patient presentation of mechanical back pain or signs of radiological instability on dynamic radiographs. The obvious limitation in this study is its retrospective nature as patients only have objective assessments up to 1-year postoperatively. Thus, the relief of symptoms can only be considered by patient interview. In addition, not all patients in our series were investigated with prone traction films. From the results, we can only conclude that radiological instability on flexion-extension radiographs is not a good investigation for segmental instability to guide treatment since patients with positive findings were treated successfully by decompression surgery alone.

\section{Conclusions}

Decompression-only surgery has its role in managing lowgrade degenerative spondylolisthesis even in the presence of mechanical back pain and radiological instability on dynamic radiographs. Fusion should not be encouraged in all cases of degenerative spondylolisthesis. The degree of instability illustrated by traction radiographs to suggest fusion surgery is still unknown as the subjects in our series enjoyed good long-term results despite slip reduction and disc height restoration. Higher level studies like ran-
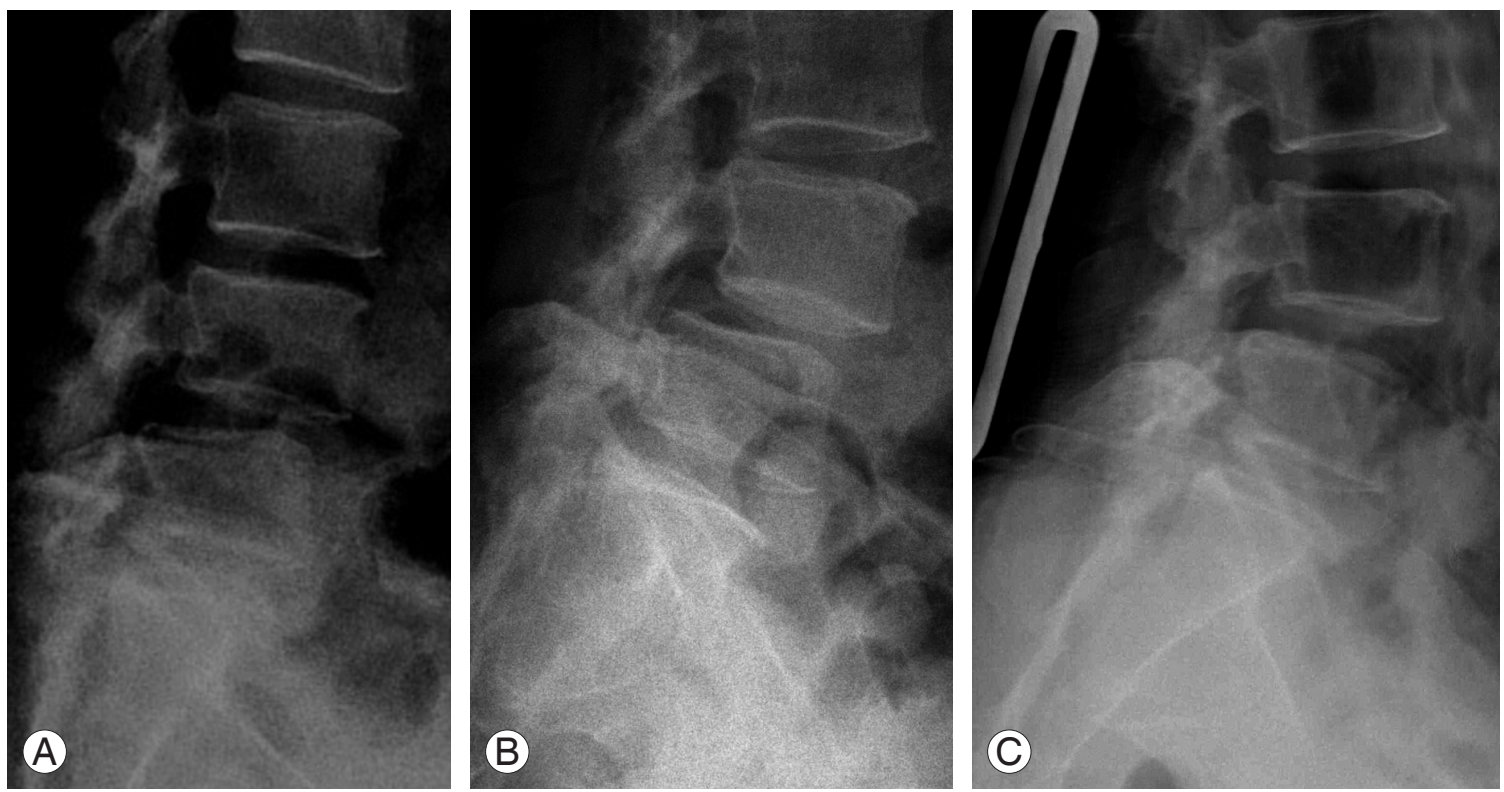

Fig. 4. L4-L5 degenerative spondylolisthesis with reduction of the slip from flexion (A) to extension (B) radiographs. Further reduction of the slip and restoration of disc height is observed on prone traction film (C). 
domized controlled trials should be performed to discern whether decompression-only surgery should be advocated for low-grade degenerative spondylolisthesis. Radiological instability parameters should be based on both flexionextension and prone traction radiographs and correlated with objective outcome assessments. These studies should be better constructed by focusing on low-grade slips instead of generalizing this highly variable condition into one entity.

\section{Conflict of Interest}

No potential conflict of interest relevant to this article was reported.

\section{References}

1. Fischgrund JS, Mackay M, Herkowitz HN, Brower R, Montgomery DM, Kurz LT. 1997 Volvo Award winner in clinical studies. Degenerative lumbar spondylolisthesis with spinal stenosis: a prospective, randomized study comparing decompressive laminectomy and arthrodesis with and without spinal instrumentation. Spine (Phila Pa 1976) 1997;22:280712.

2. France JC, Yaszemski MJ, Lauerman WC, et al. A randomized prospective study of posterolateral lumbar fusion: outcomes with and without pedicle screw instrumentation. Spine (Phila Pa 1976) 1999;24:55360.

3. Herkowitz HN, Kurz LT. Degenerative lumbar spondylolisthesis with spinal stenosis: a prospective study comparing decompression with decompression and intertransverse process arthrodesis. J Bone Joint Surg Am 1991;73:802-8.

4. Kleinstueck FS, Fekete TF, Mannion AF, et al. To fuse or not to fuse in lumbar degenerative spondylolisthesis: do baseline symptoms help provide the answer? Eur Spine J 2012;21:268-75.

5. Kornblum MB, Fischgrund JS, Herkowitz HN, Abraham DA, Berkower DL, Ditkoff JS. Degenerative lumbar spondylolisthesis with spinal stenosis: a prospective long-term study comparing fusion and pseudarthrosis. Spine (Phila Pa 1976) 2004;29:72633.

6. Mardjetko SM, Connolly PJ, Shott S. Degenerative lumbar spondylolisthesis. A meta-analysis of litera- ture 1970-1993. Spine (Phila Pa 1976) 1994;19:2256S$65 S$.

7. Pearson AM, Blood EA, Frymoyer JW, et al. SPORT lumbar intervertebral disk herniation and back pain: does treatment, location, or morphology matter? Spine (Phila Pa 1976) 2008;33:428-35.

8. Weinstein JN, Lurie JD, Tosteson TD, et al. Surgical compared with nonoperative treatment for lumbar degenerative spondylolisthesis: four-year results in the Spine Patient Outcomes Research Trial (SPORT) randomized and observational cohorts. J Bone Joint Surg Am 2009;91:1295-304.

9. Hanley EN Jr. The indications for lumbar spinal fusion with and without instrumentation. Spine (Phila Pa 1976) 1995;(24 Suppl):143S-153S.

10. Luk KD, Chow DH, Holmes A. Vertical instability in spondylolisthesis: a traction radiographic assessment technique and the principle of management. Spine (Phila Pa 1976) 2003;28:819-27.

11. Morrissy RT, Goldsmith GS, Hall EC, Kehl D, Cowie $\mathrm{GH}$. Measurement of the Cobb angle on radiographs of patients who have scoliosis: evaluation of intrinsic error. J Bone Joint Surg Am 1990;72:320-7.

12. Fang D, Cheung KM, Ruan D, Chan FL. Computed tomographic osteometry of the Asian lumbar spine. J Spinal Disord 1994;7:307-16.

13. Cheung KM, Ruan D, Chan FL, Fang D. Computed tomographic osteometry of Asian lumbar pedicles. Spine (Phila Pa 1976) 1994;19:1495-8.

14. Epstein NE. Decompression in the surgical management of degenerative spondylolisthesis: advantages of a conservative approach in 290 patients. J Spinal Disord 1998;11:116-22.

15. Hasegawa T, An HS, Haughton VM, Nowicki BH. Lumbar foraminal stenosis: critical heights of the intervertebral discs and foramina. A cryomicrotome study in cadavera. J Bone Joint Surg Am 1995;77:328.

16. Kirkaldy-Willis WH, Farfan HF. Instability of the lumbar spine. Clin Orthop Relat Res 1982;(165):11023.

17. Luk KD, Cheung KM. Lumbar spinal instability. J Orthop Surg (Hong Kong) 1998;2.

18. Dvorak J, Panjabi MM, Novotny JE, Chang DG, Grob D. Clinical validation of functional flexion-extension roentgenograms of the lumbar spine. Spine (Phila Pa 1976) 1991;16:943-50. 
19. Tallroth K, Ylikoski M, Landtman M, Santavirta S. Reliability of radiographical measurements of spondylolisthesis and extension-flexion radiographs of the lumbar spine. Eur J Radiol 1994;18:227-31.

20. Wood KB, Popp CA, Transfeldt EE, Geissele AE. Radiographic evaluation of instability in spondylolisthesis. Spine (Phila Pa 1976) 1994;19:1697-703.

21. Davis RJ, Errico TJ, Bae H, Auerbach JD. Decompression and Coflex interlaminar stabilization compared with decompression and instrumented spinal fusion for spinal stenosis and low-grade degenerative spondylolisthesis: two-year results from the prospective, randomized, multicenter, Food and Drug Administration Investigational Device Exemption trial. Spine (Phila Pa 1976) 2013;38:1529-39.

22. Panjabi MM, Krag MH, White AA, 3rd, Southwick WO. Effects of preload on load displacement curves of the lumbar spine. Orthop Clin North Am 1977;8:181-92.

23. Posner I, White AA 3rd, Edwards WT, Hayes WC. A biomechanical analysis of the clinical stability of the lumbar and lumbosacral spine. Spine (Phila Pa 1976)
1982;7:374-89.

24. Labelle H, Roussouly P, Berthonnaud E, Dimnet J, O'Brien M. The importance of spino-pelvic balance in L5-s1 developmental spondylolisthesis: a review of pertinent radiologic measurements. Spine (Phila $\mathrm{Pa}$ 1976) 2005;30:S27-34.

25. Labelle H, Roussouly P, Berthonnaud E, et al. Spondylolisthesis, pelvic incidence, and spinopelvic balance: a correlation study. Spine (Phila Pa 1976) 2004; 29:2049-54.

26. Lowe RW, Hayes TD, Kaye J, Bagg RJ, Luekens CA. Standing roentgenograms in spondylolisthesis. Clin Orthop Relat Res 1976;(117):80-4.

27. Wiltse LL, Guyer RD, Spencer CW, Glenn WV, Porter IS. Alar transverse process impingement of the L5 spinal nerve: the far-out syndrome. Spine (Phila Pa 1976) 1984;9:31-41.

28. Wiltse LL, Winter RB. Terminology and measurement of spondylolisthesis. J Bone Joint Surg Am 1983;65:768-72.

29. Friberg O. Instability in spondylolisthesis. Orthopedics 1991;14:463-5. 